\title{
Brasil e China: uma nova aliança não escrita?
}

\author{
Brazil and China: a new unwritten alliance?
}

HENRIQUE ALTEMANI DE OLIVEIRA*

Rev. Bras. Polít. Int. 53 (2): 88-106 [2010]

\section{Introdução ${ }^{1}$}

Em 2010 se completaram 36 anos do estabelecimento de relações diplomáticas entre o Brasil e a República Popular da China. Ainda que, em 1974, o Brasil estivesse sob uma ditadura militar e a China sofresse ainda os radicalismos da Revolução Cultural, ambos os governos enfatizaram as profundas diferenças entre si, ressaltando no entanto a possibilidade de uma ação conjunta no sistema internacional que permitisse atingir objetivos comuns.

Assim, desde o início a parceria sino-brasileira apresentava o objetivo de uma ação conjunta em tópicos de interesses comuns de desenvolvimento na agenda internacional, demonstrando similaridades em alguns princípios de política externa, principalmente a determinação em assegurar autonomia internacional, ênfase na soberania nacional e integridade territorial, opondo-se a qualquer tipo de interferência externa nos assuntos internos.

Apresentavam também posicionamentos similares em relação a outras questôes internacionais, tais como a oposição à diplomacia de direitos humanos dos Estados Unidos e a responsabilidade comum à cooperação multilateral SulSul, em especial a oposição ao protecionismo comercial dos países desenvolvidos.

Durante a Guerra Fria, o Brasil e a China, conscientes de sua condição de países em desenvolvimento, colaboraram no campo político-estratégico com o objetivo de exercer pressão sobre o processo de reforma das instituições multilaterais, especialmente as econômicas e financeiras. Este processo de cooperação foi expandido, em 1988, para cooperação tecnológica nas áreas da indústria aeroespacial e de mísseis.

Em 1974, o Brasil estava em um estágio de forte desenvolvimento econômico, com crescimento do PIB em dois dígitos anuais, enquanto que a China, retomando

\footnotetext{
* Professor de Relaçôes Internacionais da Pontifícia Universidade Católica de São Paulo - PUC-SP e da Universidade Estadual da Paraíba - UEPB e Coordenador do Grupo de Estudos Ásia-Pacífico - GEAP-PUC/ SP (henrique.altemani@gmail.com).

$1 \mathrm{O}$ titulo deste artigo é inspirado na obra de BURNS, E. C. A aliança não escrita: o Barão do Rio Branco e as relaçôes Brasil - Estados Unidos. Rio de Janeiro: EMC Ediçōes, 2003.
} 
modesta presença na comunidade internacional passava por um período de profundo caos econômico. A China, por sua vez, buscava igualmente um lugar próprio na política mundial. Deng Xiaoping, em 1972, anunciava o fim do Campo Socialista e se identificava como pertencendo ao Terceiro Mundo e Mao Zedong, em 1974, desenvolvia a Teoria dos Três Mundos.

Trinta e seis anos depois, ainda que o Brasil apresente índices econômicofinanceiros altamente positivos e forte ativismo nos processos negociadores internacionais, a China mantém-se em uma posição, tanto no plano econômico quanto no político-estratégico, claramente superior à brasileira.

Em decorrência da crescente dependência brasileira em relação ao mercado chinês e de seu caráter assimétrico, parte da sociedade brasileira acompanha com um misto de desilusão e ceticismo o relacionamento sino-brasileiro. A grande imprensa reproduz continuadamente este descontentamento, enfatizando as imagens de ameaça chinesa, de necessidade de estabelecimento de salvaguardas, de ingenuidade no reconhecimento da China como uma economia de mercado.

A partir da premissa de que o relacionamento sino-brasileiro esteve sempre alicerçado nos objetivos de suas respectivas políticas externas, ao mesmo tempo em sofre os impactos conjunturais tanto dos ambientes domésticos quanto do cenário internacional, a presente reflexão tem como preocupação precípua avaliar a capacidade de conversão da retórica em projetos reais e de continuidade da parceria iniciada 36 anos atrás.

Assim, o presente texto defende a idéia de que a parceria estratégica entre Brasil e China concentra-se em dois nítidos campos de atuação: um, no plano político, correlacionado às estratégias de alianças no âmbito dos fóruns multilaterais e, outro, no da cooperação científico-tecnológica, com vistas a romper o monopólio detido pelos países desenvolvidos. A perspectiva de parceria estratégica não se insere no campo das relações econômico-comerciais. Ao contrário, a China inserese gradualmente no processo econômico do Leste Asiático e reproduz a relação comercial típica do Leste Asiático com o Brasil e a América do Sul: fornecimento de produtos manufaturados em troca de minérios e produtos agrícolas.

Da mesma forma, é natural que na dimensão comercial ocorram conflitos localizados em função da competitividade bilateral ou internacional. Mas, a questão é se estes conflitos de ordem comercial afetam ou não o relacionamento sino-brasileiro nas demais dimensões. Quanto a este ponto, a presente reflexão aventa a hipótese de que tanto os reflexos dos contenciosos econômico-comerciais quanto as desconfianças nas possibilidades de manutenção da parceria políticoestratégica nos Fóruns internacionais induziram a um relativo questionamento da viabilidade de continuidade da parceria.

No entanto, a importância da China para a mais rápida recuperação brasileira e o novo posicionamento das Potências Emergentes nos processos decisórios internacionais propiciaram o reforço da parceria com a República Popular da China. 


\section{As relações políticas}

Desde o início da década de 1960, a política externa brasileira passou por um processo de mudança no que diz respeito a um dos seus anteriores paradigmas de política externa, ou seja, a aliança estratégica com os EUA. Enquanto os Estados Unidos estavam envolvidos principalmente com assuntos de segurança internacional, o Brasil naquela época começou a usar sua política externa para promover, de forma mais autônoma, o seu desenvolvimento econômico, principalmente pela diversificação de suas parcerias tanto no relacionamento com os países desenvolvidos quanto no âmbito da Cooperação Sul-Sul.

A China foi o único país da Ásia com o qual o Brasil conseguiu estabelecer laços significativos no contexto da Cooperação Sul-Sul. Após o restabelecimento das relações diplomáticas em 15 de agosto de 1974, a parceria sino-brasileira objetivou uma ação conjunta em tópicos de interesses comuns de desenvolvimento na agenda internacional.

Apesar das diferenças em relação aos sistemas políticos, ambos, Brasil e China demonstraram similaridades em alguns princípios de política externa, principalmente a determinação em assegurar a autonomia internacional, sua ênfase na soberania nacional e integridade territorial, opondo-se assim a qualquer tipo de interferência externa nos assuntos internos.

China e Brasil apresentaram também posicionamentos similares em relação a outras questôes internacionais, tais como a oposição à diplomacia de direitos humanos dos Estados Unidos e a responsabilidade comum à cooperação multilateral Sul-Sul, em especial a oposição ao protecionismo comercial dos países desenvolvidos (Shang, 2003).

$\mathrm{Na}$ sequência desta estratégia, "desde o início do governo Lula, a política externa brasileira tem se expandido com o objetivo de projetar o país como um global player político e econômico. A diplomacia presidencial imprimiu um forte ativismo político externo, buscando simultaneamente a expansão dos laços com os Estados Unidos da América (EUA) e com a Uniāo Europeia (UE); aprofundaram-se os laços com a China e com a Índia, conjuntamente com um renovado multilateralismo Sul-Sul e uma, sem precedentes, presença política na América do Sul. Não obstante este conjunto diversificado de "frentes externas" levando a uma ampliação da participação nos fóruns políticos e econômicos globais, Brasil ainda encara os constrangimentos impostos pelas assimetrias estruturais do Sistema Internacional junto com o fato de ainda fazer parte da esfera de influência dos EUA". (Hirst, 2008: 145)

Este interesse político-econômico pela Ásia apresentava também uma forte expectativa no papel que poderia ser desempenhado pela China. Como expressava o Presidente Lula, no início de seu primeiro mandato, "tenho repetido que a América do Sul será prioridade em meu governo, pois estou convencido de que o desenvolvimento pleno do Brasil só será possível como parte da integração do 
continente como um todo. (...) E se temos uma vocação regional, somos, também um país global. Da mesma forma que a integração nacional passa pela integração regional, estou convencido de que a aproximação com a Ásia e, em particular com a China, será decisiva para o Brasil realizar esse destino maior" ${ }^{2}$.

$\mathrm{O}$ relacionamento sino-brasileiro sempre se apresentou como altamente promissor pela constatação de inúmeras complementaridades no plano econômico e pela contínua presença em ambos os países de uma real vontade política de estabelecimento de uma cooperação tanto no plano bilateral quanto no multilateral.

Para os lideres chineses, a perspectiva de "mundo harmônico" correlacionase com paz e desenvolvimento. Neste sentido, China respeita as diferentes civilizações, os diferentes modos de produção e persegue ideais de igualdade, respeito, benefício mútuo e harmonia entre as diferenças. E, ainda que isto aparente ser abstrato, estabelece um roteiro para a prática diplomática, voltada não só à garantia da paz e do desenvolvimento, mas também à cooperação.

Neste sentido, o Brasil apresenta uma perspectiva de cooperação similar à visão da política externa chinesa. Isto é, o relacionamento brasileiro com o Leste Asiático, no plano geral, e com a China especificamente, tem uma expressão estratégica no seu processo de inserção internacional, com conteúdo tanto econômico quanto político.

A questão que se coloca é se a China, em função da ampliação de seu papel econômico, político e estratégico no atual contexto internacional, não passou a considerar que seu relacionamento com o Brasil deixou de ser pertinente. Este questionamento expressa o desconforto que a diplomacia brasileira passou a sentir nos primeiros anos deste século, na constatação de que China não conseguia, ou não tinha mais interesse, em transformar sua retórica em projetos efetivos.

Talvez esta questão não seja pertinente se considerarmos que o atual conceito de Cooperação Sul-Sul não apresenta o mesmo significado do período da Guerra Fria. Hoje é seletivo e hierárquico, englobando países emergentes que não visam mais mudanças estruturais na Ordem Internacional, mas uma readequação das regras de forma a possibilitar a promoção de seus respectivos interesses.

A possibilidade de cooperação tecnológica começou igualmente a ser questionada em função do fato de que cada vez mais a China detém melhores condições de investimento do que o Brasil. E mesmo a parceria política sofre críticas pelo não apoio explícito da China seja no interesse brasileiro em assumir uma cadeira permanente no Conselho de Segurança das Nações Unidas (CS/ONU), seja na interminável Rodada Doha da Organização Mundial do Comércio (OMC). Entretanto, o problema não é o apoio da China, mas se, quando e como China (e os outros Estados) vai apoiar a reforma do Conselho de Segurança da ONU.

2. Discurso do Senhor Presidente da República, Luiz Inácio Lula da Silva, na solenidade de Abertura do Seminário Brasil - China: "Um Salto Necessário" - BNDES - Rio de Janeiro, 30 de abril de 2003. IN: Palavra Internacional do Brasil, 02/05/2003. Http://www.relnet.com.br 
Com o objetivo de minimizar as crescentes tensões no relacionamento bilateral, foram desenvolvidos alguns mecanismos bilaterais, como a Comissão Sino-Brasileira de Alto Nível de Concertação e Cooperação (COSBAN), em 2006, com a responsabilidade de coordenação de diversas vertentes do relacionamento bilateral e o Diálogo Estratégico, em 2007 (Becard, 2009: 177).

De outro lado, no entanto, aparentemente também está claro que o processo de inserção e desenvolvimento chinês tinha e ainda tem como objetivo final a busca da garantia da sobrevivência integral e autônoma do Estado Chinês e do Partido Comunista. E que para a consecução deste objetivo a China não faz transigências, colocando acima de tudo a defesa do interesse nacional. E, por fim, a consciência também de que o êxito de seu modelo de desenvolvimento é dependente da aceitação das regras do jogo internacional.

No entanto, estas regras não são imutáveis, ao contrário representam o resultado de um lento processo negociador e, conseqüentemente, interessa à China participar dos diferentes fóruns negociadores e buscar apoio às suas pretensóes.

No plano da percepção dos interesses políticos e da disputa entre as principais potências, China considera que seu desenvolvimento está diretamente correlacionado com o confronto, no espaço asiático, entre Estados Unidos e Japão, com a Índia assumindo um papel de coadjuvante nesta equação, e, no espaço global, ao impasse observado entre estas duas potências mais a União Europeia.

Esta aparente contradição entre uma China forte e uma China frágil e vulnerável, mas principalmente a contradição entre uma China que busca manter sua autonomia e uma China dependente do Sistema Internacional constitui a principal base para o raciocínio de que o relacionamento sino-brasileiro esteve e ainda está alicerçado na percepção mútua da importância que a estratégia de Cooperação Sul-Sul apresenta para os dois países e para suas respectivas políticas externas.

Apesar da maior relevância que a China assumiu nos últimos anos, expressa essencialmente após sua acessão à OMC em 2002, o país mantém ainda uma série de problemas que impedem o raciocínio de que é uma potência internacional consolidada. Em primeiro, os desafios de expandir seu crescimento para outras regiōes além da região costeira, propiciando uma distribuição de renda mais eqüitativa e agregar a população camponesa ao processo de crescimento doméstico. Além desta realidade de desigualdades econômicas, não se pode esquecer os problemas de fornecimento de energia e de água, a ausência de uma política de seguro social, a degradação ambiental, a especulação imobiliária, as práticas de falsificação, contrabando e corrupção.

E, no plano internacional, as fragilidades decorrentes da manutenção de um Estado socialista, com um governo mantido por um partido comunista e as decorrentes das questôes de não respeito aos direitos humanos e exploração de mão-de-obra infantil, entre outras. 
Neste contexto, considera-se a permanência da consciência (vontade) política para o desenvolvimento de mecanismos que possam possibilitar a construção de parcerias mais vantajosas a ambos os participantes. China tem o Brasil como um parceiro estratégico, neste mesmo processo de redefinição do sistema e da ordem internacionais, na consideração de que ainda são atores intermediários. Desta forma, as parcerias tecnológicas e políticas, mormente no campo multilateral, são fundamentais.

A crise financeira internacional, escancarada no final de 2008, bem como os impasses na Rodada Doha da OMC deixaram por demais clara a fragilidade das atuais instituições existentes (com suas regras) e a necessidade de drásticas mudanças para re-acomodação dos interesses dos diferentes Estados, de forma a gerar um ambiente mais cooperativo e estável no plano internacional.

A economia brasileira certamente sentiu o aperto da crise econômica global, mas quatro respostas podem ser consideradas como fundamentais para a superação mais rápida: o controle exercido pelo governo brasileiro, a capacidade de efetuar as reformas necessárias para promover o crescimento de longo prazo, a diversidade de seus parceiros econômicos e a manutenção da forte demanda chinesa.

A crise econômico-financeira, os papéis desempenhados pela China e pelo Brasil nos processos de recuperação econômica doméstica e internacional, assim como a consolidação do G20, em setembro de 2009, como conselho decisório da economia mundial possibilitaram reforço dos laços e da parceria estratégica entre Brasil e China, propiciando o compromisso informal de retomada da perspectiva de uma posição comum nas instituições internacionais.

De acordo com Cesarin (2009: 25-26), para a China, as Potências Emergentes constituem uma plataforma para construir poder e influência combinando esforços junto a potências do Sul com o objetivo de fixar novas regras do jogo a nível mundial mediante uma instância multilateral. Já a Índia apresenta uma estratégia mais ampla de fortalecimento de suas relações bilaterais ou trilaterais com Estados proeminentes e com organizações regionais. E, na perspectiva brasileira, as Potências Emergentes são uma expressão do interesse para associar-se com atores determinantes no cenário internacional, promover o multilateralismo e favorecer seu reconhecimento como líder regional e potência global.

A pressão para a China assumir um papel de liderança internacional é suavizada pelo fato de que não é só a China que está sendo demandada, mas o conjunto dos países atualmente chamados de potências emergentes, embora a China tenha expressão econômica, política e estratégica claramente superior à capacidade destes outros países, os quais apresentam uma plataforma relativamente similar: uma distribuição mais justa do poder, refletindo um mundo multipolar e sua crescente posição na hierarquia internacional.

Depois do auge da crise financeira internacional, o Brasil e a China ampliaram fortemente a sua política de parceria com o objetivo de expandir as 
suas capacidades nos mecanismos internacionais de tomada de decisões. O recémcriado G20 possibilitou que tanto o Brasil quanto a China, não membros do G8, pudessem ampliar suas participações nas decisões financeiras internacionais. Ambos os países, apesar de interesses diferentes, mostram forte interesse em reativar a Rodada Doha da OMC, como forma de promover ajustes no comércio internacional que melhor atendessem as expectativas do Sul.

Neste sentido, a crise econômico-financeira possibilitou o reforço dos laços e da parceria estratégica entre Brasil e China, propiciando o compromisso informal de retomada da perspectiva de uma posição comum nas instituiçôes internacionais.

O Plano de Ação Conjunta que os presidentes Luiz Inácio Lula da Silva e Hu Jintao assinaram em abril de 2010 visa dar caráter institucional à relação entre Brasil e China, com o estabelecimento de metas e a criação de mecanismos permanentes de consulta e coordenação entre os dois países.

Esta perspectiva corresponde plenamente à estratégia brasileira de negociação de seu espaço no Sistema Internacional e está baseada no princípio de que, apesar de suas assimetrias e diferenças, os países emergentes do Sul apresentam a similaridade de contarem com um sistema de comércio que privilegia os interesses dos países do Norte e que, conseqüentemente, é necessária uma ação conjunta para tentar ampliar as possibilidades do Sul. Daí então a atual ênfase brasileira na constituição de coalizôes ou a importância da parceria com a República Popular da China, seja sob o signo de Cooperação Sul-Sul, de Parceria Estratégica ou de Potências Emergentes.

Note-se que a ação internacional brasileira apresenta um conjunto de normas e atitudes - pacifismo, não intervencionismo, defesa da igualdade soberana das naçôes - associado ao comportamento internacional do país. De um lado, a política externa brasileira apresenta uma íntima relação com os objetivos econômicos e de de desenvolvimento do país e um compromisso com o multilateralismo. E, por outro lado, um dos fatores mais importantes para a formação política externa do Brasil tem sido a sua localização no hemisfério ocidental, com o contexto regional representando uma fonte de estabilidade para o Brasil.

Nesse sentido, o relacionamento político brasileiro com a China expressa a promoção dos seus interesses econômicos e a necessidade percebida de reformar o sistema internacional, sem qualquer direcionamento anti-hegemônico ou mesmo sem quaisquer motivações ideológicas.

\section{Relações econômico-financeiras e tecnológicas}

Com a consolidação dos dados de comércio exterior de 2009 a República Popular da China passou a ser o principal parceiro comercial do Brasil, ultrapassando na soma das exportações e importações uma posição mantida por 80 anos pelos Estados Unidos. 
Destaca-se ainda o fato da Ásia ter se tornado, pela primeira vez, o principal destino das exportaçóes brasileiras (25.8\%), deslocando o tradicional posto mantido pela União Européia (22.3\%), sendo que esta maior importância da Ásia foi decorrente, em especial, do crescimento das exportações para a China $(+23.1 \%)$.

Como a Ásia é igualmente a principal origem das importações brasileiras (28.3\%), transformou-se igualmente no principal parceiro comercial do Brasil, em termos de blocos econômicos.

No entanto, a maior presença chinesa na balança comercial brasileira levanta três expressivos questionamentos. O primeiro, como classificam Barbosa \& Tepassê (2009: 207-218), corresponde a uma marcada interdependência assimétrica. Isto é, no conjunto dos principais produtos exportados da China para o Brasil, a participação brasileira na venda destes produtos representa um percentual relativamente marginal (aproximadamente 2\%), enquanto que nas exportações brasileiras de minérios de ferro e de soja, a China representa $32 \%$ e $42 \%$ das vendas externas brasileiras. É assim inegável que é exatamente nestes dois setores que reside o principal interesse chinês no relacionamento comercial com o Brasil, ou seja a manutenção de fontes de fornecimento seguras, contínuas e estáveis.

Em segundo, o fato das exportaçôes brasileiras estarem concentradas em produtos básicos, de baixo valor agregado, enquanto que as importações brasileiras são essencialmente de manufaturados, em especial de bens industriais. Do total de exportações brasileiras para a China em 2009, 76,8\% correspondeu a produtos básicos, enquanto que para o mundo este índice esteve em torno de $30 \%$.

Em terceiro, mercados externos anteriormente abastecidos por exportações brasileiras de produtos manufaturados, em especial bens industriais, estão sendo crescentemente deslocados pela maior presença chinesa. Este efeito deslocamento está muito mais acentuado na América Latina, mas abrange outras regiōes como África e Oriente Médio.

Com o objetivo de gerar um ambiente mais cooperativo e que pudesse reduzir os constrangimentos decorrentes da forte assimetria no relacionamento comercial, algumas iniciativas governamentais foram desenvolvidas como a Agenda China e o Diálogo Financeiro Brasil-China, em 2008, complementando a anterior criação em 2004 do Conselho Empresarial Brasil-China (CEBC) constituído pelas principais empresas chinesas e brasileiras. (Becard, 2009: 177)

Ainda conforme Becard (2009: 180), a Agenda China objetivava tanto aprofundar a reflexão sobre a parceria sino-brasileira quanto traçar estratégias para dinamizar o comércio bilateral e ampliar investimentos mútuos, além de fomentar estudos técnicos e ações de promoção do potencial produtor e exportador brasileiro no mercado chinês, respondendo à necessidade de definição de uma estratégia mais coordenada que evidenciasse não apenas a tecnologia brasileira aplicada na área energética e de produtos primários, mas também 
outros segmentos igualmente sofisticados tecnologicamente e pouco conhecidos no mercado chinês. A Agenda China é ainda complementada por iniciativas de atração de investimentos chineses em ações direcionadas ao desenvolvimento econômico do Brasil, em especial em infra-estrutura e logística.

Mesmo havendo consciência de que a maior expressão econômico-comercial chinesa é relativamente recente (em especial após sua acessão à $\mathrm{OMC}$ ), cresceu o desconforto no Brasil pelos baixos investimentos chineses que não acompanham sua forte presença comercial no país.

No entanto, em 2009 a China passou a fazer parte do Banco Interamericano de Desenvolvimento (BID), sendo que no momento de seu ingresso, o Banco de Desenvolvimento da China e o China Eximbank fecharam acordos com o BID para participar do financiamento de projetos na América Latina. De acordo com as declaradas intençõos chinesas de ampliar investimentos na região, como bem demonstram a presença no BID e os acordos com empresas petrolíferas da região, observou-se igualmente interesse chinês em ampliar sua presença no Brasil e, em especial, no financiamento de obras governamentais projetadas pelo PAC (Programa de Aceleração do Crescimento).

É consensual que "os investimentos chineses ainda são insignificantes em termos de produção doméstica e de emprego, especialmente quando comparados com os investimentos adiados, possivelmente como resultado de um número crescente de multinacionais ter optado por concentrar suas produçôes na China. É claro que as operações regionais de várias destas empresas estão baseadas no Brasil, mas seus planos de expansão para ocupar os mercados mundiais são afetados, em certa medida, pelo dinamismo do mercado chinês e pelos níveis de competitividade que a China consegue alcançar nos mercados externos”..(Barbosa, 2008: 13)

No pós-crise, a China com fortes reservas internacionais passou a apresentar uma tendência crescente para a internacionalização de suas empresas e de expansão intensiva do investimento directo externo.

Consequentemente, o China Development Bank concedeu um empréstimo de US $\$ 10$ bilhōes para a Petrobras em maio de 2009. E entre 2009 e início de 2010, a intenção de investimentos chineses no Brasil foi muito mais clara, especialmente nos setores de petróleo, energia, mineração, agricultura, automóveis e máquinas. Assim, em maio de 2010, a State Grid adquiriu sete empresas de energia elétrica por U\$ 1,726 bilhões. No mesmo mês, Sinochen desembolsou US\$ 3,07 bilhões dólares por $40 \%$ do campo petrolífero de Peregrino em Campos-RJ. E em março, a empresa estatal ECE comprou por US\$ 1,2 bilhão a Itaminas Comércio de Minérios. E a Wuhan Iron \& Steel anunciou um acordo para construir uma usina de aço por US\$ 3,29 bilhōes.

Mesmo assim, frente ao cenário de deslocamento de colocações de produtos nos mercados interno e externo e ao crescimento de pressóes internas, o Brasil passou a ampliar a aplicação de direitos antidumping sobre produtos chineses, o que Jiang Shixue (2003: 322) considera como uma prática que constitui um 
obstáculo a mais para o estreitamento de relaçôes. Dentre as medidas em vigor no final de 2009, 26 (38.2\%) de um total de 68 eram sobre produtos chineses.

Polêmico e contencioso no relacionamento comercial sino-brasileiro é o fato do Brasil ter reconhecido, em 2004, a China como economia de mercado, ao contrário do conceito de economia em transição que tinha sido atribuído à China pela OMC. Considerado como um fator inibidor de estabelecimento de salvaguardas comerciais em caso de dumping ou subsídios, o reconhecimento gerou e continua gerando uma extensa série de discordâncias por parte de setores produtivos que se consideram prejudicados pela concorrência chinesa.

Independentemente de considerações acadêmicas ou econômicas, esta decisão foi eminentemente política e atrelada ao conceito de parceria estratégica, por intermédio da qual se vislumbra a possibilidade de ação em conjunto com a China no processo de redefinição da ordem internacional. No entanto, como esta decisão não foi ainda regulamentada pela Câmara de Comércio Exterior (CAMEX), o Brasil se considera desobrigado de aplicação, tratando a China como economia em transição ou economia planificada.

A parceria sino-brasileira ganhou um contorno mais definido na área de cooperação técnica e científico-tecnológica, com o trabalho conjunto para o desenvolvimento de satélites de sensoriamento remoto (China-Brazil Earth Resources Satellite - CBERS). Destaca-se o fato de que o projeto de cooperação espacial teve significado especial para o governo chinês por se tratar de um modelo de cooperação Sul-Sul, uma das prioridades da ação diplomática chinesa. Não havendo, até o momento, nenhum projeto de cooperação similar no segmento de satélites entre as nações em desenvolvimento, tampouco na cooperação Norte-Sul (CUNHA 2004: 79).

Firmado inicialmente em 1988, o acordo foi ampliado em 1995, planejandose produzir mais dois satélites, além dos inicialmente previstos. Pressupunha-se que os satélites permitiriam aos dois países uma independência na área de imagens por satélites, possibilitando-os inclusive a passar de usuários a exportadores desse tipo de serviço. O primeiro satélite (CBERS-1) foi lançado em 1999 e o segundo (CBERS-2) teve seu lançamento em 2003.

Já o terceiro (CBERS-2B) foi lançado em 2007 e deu início a um novo programa de monitoramento da Amazônia. O sistema utiliza imagens do satélite para detectar e fiscalizar o corte seletivo de madeira, no qual apenas as árvores de maior valor comercial são removidas, sem destruição da cobertura florestal, o que dificulta a observação via satélite. O sistema de Detecção de Exploração Florestal Seletiva (Detex) passou a ser um dos mecanismos de monitoramento do programa de concessão de florestas públicas federais. Estão ainda previstos os lançamentos dos CBERS-3 e 4 em 2011 e 2014.

Destaca-se ainda a cooperação chinesa com a EMBRAPA (Empresa Brasileira de Pesquisa Agropecuária) em especial no que se refere ao aprofundamento dos conhecimentos sobre os sistemas de controle sanitário e fitossanitário local para 
adequar os produtos brasileiros às exigências dos mercados da região, com ênfase no acesso aos bancos de recursos genéticos para ampliar as pesquisas com materiais de soja, assim como de produtos mais tradicionais como legumes, cogumelos e frutas, além da intensificação dos contatos para produção de etanol.

A cooperação está ainda sendo estendida a outros setores, como biotecnologia, informática e desenvolvimento de novos materiais. E na área de saúde estão em andamento iniciativas conjuntas no combate à AIDS, na produção e comercialização de produtos farmacêuticos genéricos e remédios de medicina tradicional e na pesquisa de novos medicamentos.

Ainda em 2009, a Universidade Federal do Rio de Janeiro, por meio da Coordenação dos Programas de Pós Graduação de Engenharia (Coppe), inaugurou centro de pesquisa em Pequim e firmou parceria com a Universidade de Tsinghua, a fim de desenvolver projetos acadêmicos comuns e aumentar cooperação tecnológica - especialmente em biotecnologia, mudanças climáticas e exploração de petróleo offshore.

O Centro Brasil-China de Tecnologias Inovadoras, como é chamada a instituição de pesquisa, também catalogará fontes de biodiesel comuns a ambos os países com objetivo de desenvolver projetos conjuntos. A parceria, com apoio do BNDES, dos Ministérios das Relaçôes Exteriores e de Ciência e Tecnologia e do Conselho Empresarial Brasil-China, reflete interesse chinês em aproximar-se de países latino-americanos, ricos em recursos considerados estratégicos, a fim de garantir fornecedores estáveis e de longo prazo desses produtos.

\section{As relações comerciais}

No plano estritamente comercial, a política externa brasileira, desde o início dos anos 1960, apresenta uma característica constante direcionada ao objetivo de manutenção de relações comerciais diversificadas, de forma a evitar dependências muito acentuadas de um país ou de uma região. $\mathrm{Na}$ realidade, busca-se preservar e aprofundar a natureza multilateral da inserção econômica brasileira.

Desta forma, nos últimos anos pode-se detectar um fluxo comercial brasileiro tendendo a manter um relativo equilíbrio entre os principais parceiros comerciais: Estados Unidos, União Européia, ALADI (Associação Latino-Americana de Integração) e Ásia, mas com uma tendência expressiva do crescimento da importância asiática na balança comercial brasileira.

Em 2009, 10.2\% das exportações brasileiras foram para os Estados Unidos e $22.3 \%$ para a União Européia. A ALADI foi responsável por 19.5\%, a Ásia por $25.8 \%$ e o resto do mundo por $22.2 \%$. Assim, todas as principais áreas do mundo são importantes mercados para o Brasil. (Tabelas 1 e 2).

No que diz respeito ao destino das exportaçóes brasileiras, em primeiro, a China em 2009 ultrapassou os Estados Unidos, tornando-se o principal mercado para o Brasil e, em segundo, a Ásia ultrapassou também a União Europeia. 
Tabela 1

Brasil: Exportações para Mercados Selecionados

\begin{tabular}{|c|c|c|c|c|c|c|c|}
\hline Ano & $\begin{array}{c}\text { ALADI } \\
\%\end{array}$ & $\begin{array}{c}\text { EUA } \\
\%\end{array}$ & $\begin{array}{c}\text { UE } \\
\%\end{array}$ & $\begin{array}{c}\text { ÁSIA } \\
\%\end{array}$ & $\begin{array}{c}\text { China } \\
\%\end{array}$ & $\begin{array}{c}\text { Japão } \\
\%\end{array}$ & $\begin{array}{c}\text { Outros } \\
\%\end{array}$ \\
\hline 1990 & 10.4 & 24.2 & 32.4 & 16.9 & 1.2 & 7.5 & 16.1 \\
1995 & 21.5 & 18.7 & 27.8 & 17.6 & 2.6 & 6.7 & 14.4 \\
2000 & 23.4 & 24.7 & 26.8 & 11.5 & 2.0 & 4.5 & 13.6 \\
2001 & 21.0 & 24.7 & 25.5 & 11.9 & 3.3 & 3.4 & 16.9 \\
2002 & 16.4 & 25.7 & 25.0 & 14.6 & 4.2 & 3.5 & 18.3 \\
2003 & 17.7 & 23.1 & 24.8 & 16.0 & 6.2 & 3.2 & 18.4 \\
2004 & 20.4 & 21.1 & 25.0 & 15.1 & 5.6 & 2.9 & 18.4 \\
2005 & 21.5 & 19.2 & 22.4 & 15.7 & 5.8 & 2.9 & 21.2 \\
2006 & 22.8 & 17.8 & 22.1 & 15.1 & 6.1 & 2.8 & 22.2 \\
2007 & 22.7 & 15.8 & 25.2 & 15.6 & 6.7 & 2.7 & 20.7 \\
2008 & 21.8 & 13.9 & 23.4 & 18.9 & 8.3 & 3.1 & 24.1 \\
2009 & 19.5 & 10.2 & 22.3 & 25.8 & 13.2 & 2.8 & 22.2 \\
\hline
\end{tabular}

Fonte: MDIC (www.mdic.gov.br)

Tabela 2

Brasil: Importações de Mercados Selecionados

\begin{tabular}{|c|c|c|c|c|c|c|c|}
\hline Ano & $\begin{array}{c}\text { ALADI } \\
\%\end{array}$ & $\begin{array}{c}\text { EUA } \\
\%\end{array}$ & $\begin{array}{c}\text { UE } \\
\%\end{array}$ & $\begin{array}{c}\text { ÁSIA } \\
\%\end{array}$ & $\begin{array}{c}\text { China } \\
\%\end{array}$ & $\begin{array}{c}\text { Japão } \\
\%\end{array}$ & $\begin{array}{c}\text { Outros } \\
\%\end{array}$ \\
\hline 1990 & 17.7 & 21.3 & 22.3 & 8.6 & 0.6 & 6.0 & 30.1 \\
1995 & 20.0 & 21.1 & 27.7 & 16.5 & 2.1 & 6.6 & 14.7 \\
2000 & 20.9 & 23.1 & 25.2 & 15.4 & 2.2 & 5.3 & 15.4 \\
2001 & 18.0 & 23.5 & 26.7 & 16.1 & 2.4 & 5.5 & 15.7 \\
2002 & 17.4 & 22.1 & 27.8 & 16.9 & 3.3 & 5.0 & 15.8 \\
2003 & 17.0 & 20.2 & 28.3 & 18.5 & 4.5 & 5.2 & 16.0 \\
2004 & 16.0 & 18.3 & 25.4 & 19.6 & 5.9 & 4.6 & 20.7 \\
2005 & 15.7 & 17.5 & 24.7 & 22.9 & 7.3 & 4.6 & 20.2 \\
2006 & 17.9 & 16.1 & 22.0 & 25.0 & 8.7 & 4.2 & 19.0 \\
2007 & 17.1 & 15.7 & 22.2 & 26.0 & 10.5 & 3.8 & 20.0 \\
2008 & 15.8 & 14.8 & 20.9 & 27.3 & 11.6 & 3.9 & 21.2 \\
2009 & 17.1 & 15.7 & 22.9 & 28.3 & 12.5 & 4.2 & 16.0 \\
\hline
\end{tabular}

Fonte: MDIC (www.mdic.gov.br)

Com as novas parcerias comerciais seria óbvio esperar uma relativa perda de importância do Japão no conjunto do intercâmbio comercial brasileiro com a Ásia. No entanto, o fato que mais chama atenção é o grande desenvolvimento do relacionamento com a China, superando desde 2002 as exportaçóes japonesas e desde 2004 as importaçôes. Enquanto o Japão recebia, em 2000, 4.5\% do total 
das exportações e a China 2.0\%, em 2009 a China foi responsável por 13.2\% das exportações brasileiras e o Japão por $2.8 \%$. No total das importações brasileiras, o Japão, no mesmo período, era o fornecedor de $5.3 \%$, passando para $4.2 \%$ em 2009 , enquanto que a China evoluiu de $2.2 \%$ para $12.5 \%$ no mesmo período. (Gráficos 1 e 2).

\section{Gráfico 1}

Exportações Brasileiras para China e Japão (em \%)

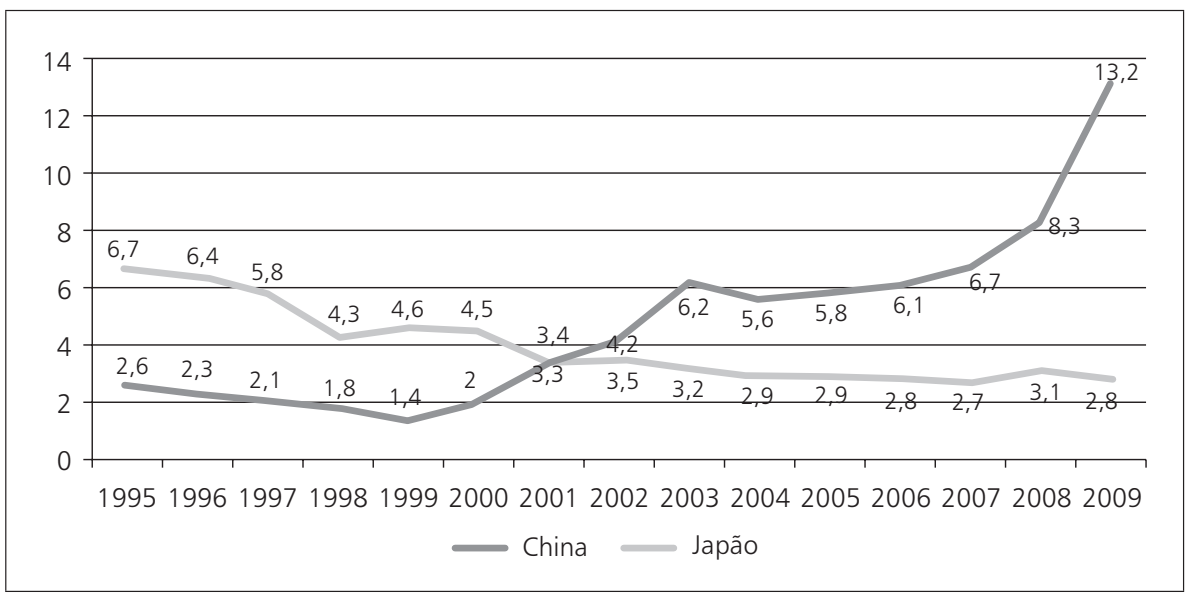

Fonte: MDIC (www.mdic.gov.br)

Gráfico 2

Importações Brasileiras para China e Japão (em \%)

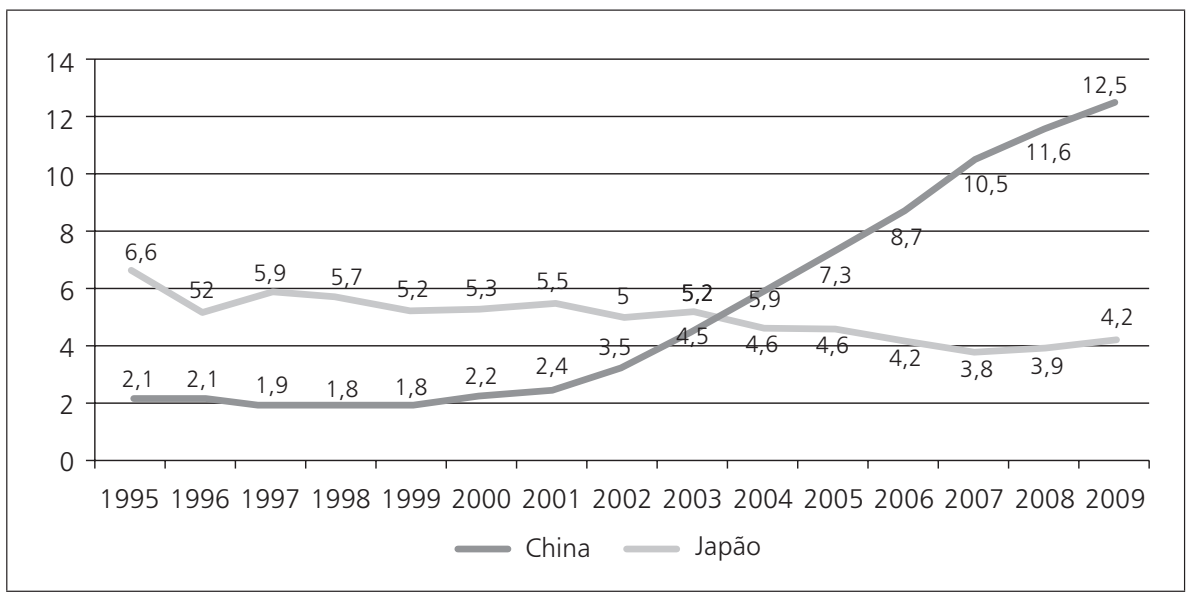

Fonte: MDIC (www.mdic.gov.br) 
Pode-se afirmar que há, entre os diferentes países asiáticos, um padrão comercial similar de relacionamento com o Brasil. De um lado, o Brasil évisualizado como fonte supridora de matérias-primas, principalmente produtos alimentícios e insumos básicos. De outro, é um cliente de produtos manufaturados.

De uma forma genérica, China, Japão e Coréia do Sul são compradores de minérios de ferro e seus concentrados, produtos de ferro e aço e soja em grão ou óleo de soja. Japão é ainda um forte comprador de alumínio e, nos últimos anos, de pedaços de frango.

Enquanto, em 2008, as commodities representaram 38.3\% do total das exportações brasileiras, as exportações deste mesmo grupo de produtos para a Ásia corresponderam a $62.5 \%$. Ainda que os países asiáticos absorvam preferencialmente commodities, a China apresenta uma tendência mais acentuada do que a dos demais países (China - 77.5\%, Japão - 67.3\%).

Já as importações brasileiras provenientes da Ásia consistem principalmente de produtos eletrônicos, produtos manufaturados e máquinas pesadas. (Tabelas 3 e 4).

Tabela 3

Brasil: Exportações por categoria de produtos e por destino, 2008

\begin{tabular}{|c|c|c|c|c|c|c|c|}
\hline & ALADI & EUA & UE & ÁSIA & China & Japão & Total \\
\hline Valor em US\$ bi & 49,977 & 27,735 & 46,459 & 37,981 & 16,403 & 6,114 & 197,942 \\
\hline Total & $100 \%$ & $100 \%$ & $100 \%$ & $100 \%$ & $100 \%$ & $100 \%$ & $100 \%$ \\
\hline Produtos Primários & 20.2 & 23.8 & 46.3 & 62.5 & 77.5 & 67.3 & 38.3 \\
\hline Manufaturas baseadas em Recursos Naturais & 15.3 & 21.6 & 25.4 & 14.1 & 12.2 & 18.8 & 20.4 \\
\hline Manufaturas de Baixa Tecnologia & 10.7 & 9.0 & 7.0 & 3.5 & 2.6 & 1.9 & 6.9 \\
\hline Manufaturas de Média Tecnologia & 43.4 & 29.3 & 16.1 & 16.4 & 5.6 & 11.2 & 24.5 \\
\hline Manufaturas de Alta Tecnologia & 10.0 & 14.2 & 4.2 & 3.5 & 2.1 & 0.6 & 6.9 \\
\hline
\end{tabular}

Fonte: CEPAL, International Commerce and Integration Division (www.cepal.org/comercio)

Exportações Brasil-China por Produto (em \%)

\begin{tabular}{|l|c|c|c|c|c|c|c|c|c|c|}
\hline & 2000 & 2001 & 2002 & 2003 & 2004 & 2005 & 2006 & 2007 & 2008 & 2009 \\
\hline Soja & 31.1 & 28.3 & 32.8 & 29.0 & 30.0 & 25.1 & 29.0 & 26.4 & 32.4 & 31.4 \\
Óleo de Soja & 2.0 & 0.3 & 5.0 & 5.9 & 9.1 & 2.5 & 1.4 & 2.9 & 5.0 & 2.0 \\
Minérios de Ferro não & & & & & & & & & & \\
$\quad$ Aglomerados & 16.2 & 17.9 & 16.5 & 11.5 & 14.4 & 18.2 & 25.5 & 29.0 & 25.0 & 31.5 \\
Minérios de Ferro Aglomerados & 8.8 & 7.5 & 7.2 & 5.4 & 6.1 & 7.9 & 5.8 & 5.5 & 4.7 & 3.3 \\
Pasta Química de Madeira & 5.0 & 6.7 & 4.5 & 5.9 & 4.9 & 4.0 & 4.1 & 3.6 & 3.7 & 4.4 \\
Óleos Brutos de Petróleo & 3.3 & 2.1 & - & 0.5 & 3.9 & 7.9 & 10.0 & 7.8 & 10.3 & 6.6 \\
Couros & 2.2 & 2.9 & 2.7 & 2.5 & 3.3 & 3.5 & 4.4 & 4.5 & 1.7 & 1.6 \\
Demais Produtos & 31.4 & 34.3 & 31.3 & 39.3 & 28.3 & 31.2 & 19.8 & 20.3 & 17.2 & 19.2 \\
Total em US\$ 1.000.000 FOB & 1.086 & 1.902 & 2.520 & 4.532 & 6.439 & 6.833 & 8.399 & 10.749 & 16.403 & 20.191 \\
\hline
\end{tabular}

Fonte: MDIC (www.mdic.gov.br) 
Tabela 4

Brasil: Importações por categoria de produtos e por origem, 2008

\begin{tabular}{|l|c|c|c|c|c|c|c|}
\hline & ALADI & EUA & UE & ÁSIA & China & Japão & Total \\
\hline Valor em US\$ bi & 28,409 & 25,850 & 36,215 & 48,069 & 20,040 & 6,807 & 173,197 \\
Total & $100 \%$ & $100 \%$ & $100 \%$ & $100 \%$ & $100 \%$ & $100 \%$ & $100 \%$ \\
Produtos Primários & 30.0 & 7.2 & 2.1 & 4.4 & 1.5 & 0.1 & 18.5 \\
Manufaturas baseadas em & & & & & & & \\
$\quad$ Recursos Naturais & 27.3 & 19.6 & 18.6 & 16.7 & 13.2 & 10.3 & 18.7 \\
Manufaturas de Baixa Tecnologia & 4.0 & 6.3 & 8.8 & 13.7 & 18.8 & 8.4 & 7.7 \\
Manufaturas de Média Tecnologia & 33.6 & 44.9 & 49.9 & 29.3 & 26.0 & 58.7 & 36.0 \\
Manufaturas de Alta Tecnologia & 4.8 & 21.6 & 20.2 & 35.6 & 40.3 & 22.4 & 18.9 \\
\hline
\end{tabular}

Source: CEPAL, International Commerce and Integration Division (www.cepal.org/comercio)

\section{Importações Brasil-China por Produto (em \%)}

\begin{tabular}{|l|c|c|c|c|c|c|c|c|c|c|}
\hline & 2000 & 2001 & 2002 & 2003 & 2004 & 2005 & 2006 & 2007 & 2008 & 2009 \\
\hline Componentes de Aparelhos & & & & & & & & & & \\
$\quad$ transmissores e receptores (85) & 14.6 & 18.8 & 20.1 & 22.6 & 29.1 & 30.8 & 29.8 & 25.0 & 19.0 & 19.7 \\
Máquinas, Aparelhos e & & & & & & & & & & \\
$\quad$ Instrumentos mecânicos (84) & 9.1 & 8.6 & 5.1 & 4.6 & 5.6 & 7.2 & 9.3 & 10.2 & 7.7 & 9.9 \\
Produtos Têxteis & 0.8 & 2.4 & 2.3 & 4.0 & 3.9 & 3.6 & 2.9 & 2.9 & 1.8 & 2.2 \\
Brinquedos & 4.7 & 3.5 & 2.3 & 0.7 & 0.7 & 1.8 & 1.9 & 0.6 & 0,6 & 0,6 \\
Calçados (64) & 1.0 & 0.8 & 1.0 & 1.2 & 0.8 & 0.5 & 0.4 & 0.5 & 0.5 & 0.6 \\
Coques de hulha, linhita ou turfa & 6.1 & 9.5 & 13.0 & 11.1 & 9.6 & 3.1 & 1.4 & 1.6 & 3.0 & 0.5 \\
Dispositivos de Cristais & & & & & & & & & & \\
$\quad$ Líquidos (LCD) & 3.3 & 1.3 & 2.2 & 3.8 & 4.3 & 4.8 & 3.6 & 4.0 & 4.1 & 2.7 \\
Demais Produtos & 63.7 & 56.4 & 56.2 & 55.8 & 50.3 & 53.0 & 54.3 & 55.2 & 63.3 & 63.8 \\
Total em US\$ 1.000 FOB & 1.222 & 1.328 & 1.554 & 2.147 & 3.710 & 5.353 & 7.989 & 12.618 & 20.044 & 15.911 \\
\hline
\end{tabular}

Fonte: Brasil, MDIC

$\mathrm{Na}$ balança comercial bilateral com a Ásia, o Brasil manteve constantes superávits até 1994, quando passou a apresentar tendência de déficits até 2001. Já em 2002, com a explosão do crescimento chinês, retomou-se o histórico de superávits, entretanto, só até inclusive 2005. Assim, em 2006, a balança bilateral anotou déficit de US\$2,072 bilhões, em 2007 de US\$ 5,628 bilhões e em 2008 de US\$ 3,637.

Note-se, no entanto, que está tendência negativa não se deve exclusivamente à agressiva competitividade comercial chinesa, mas a uma tendência brasileira de aproveitamento da maior ampliação de oferta de produtos no mercado internacional, em especial para atendimento de demandas do setor produtivo nacional, e igualmente à valorização cambial do real em relação ao dólar. Constatase que, no caso das importações chinesas o setor com maior peso nas importaçôes não é o de produtos de consumo, mas de bens industriais. 
O ano de 2009, no entanto, foi atípico em decorrência da crise financeira global, com a tendência internacional generalizada de reduzir importações. Mesmo assim, as demandas por parte da China, Hong Kong, Índia e ASEAN possibilitaram que Brasil apresentasse superávit na balança comercial bilateral de 2009.

Balança Comercial Brasil-Ásia - 2009

\begin{tabular}{|l|r|r|r|}
\hline & Exportações & Importações & Saldo \\
\hline Japão & 4.269 .695 & 5.367 .570 & $(1.097 .875)$ \\
China & 20.190 .831 & 15.911 .146 & 4.279 .686 \\
Taiwan & 961.025 & 2.413 .221 & $(1.452 .196)$ \\
Hong Kong & 1.865 .298 & 529.341 & 1.335 .957 \\
Coréia do Sul & 2.622 .285 & 4.818 .447 & $(2.196 .162)$ \\
Índia & 3.415 .040 & 2.190 .899 & 1.224 .142 \\
ASEAN & 5.068 .102 & 4.667 .182 & 400.920 \\
Total Ásia & 39.425 .990 & 36.141 .515 & 3.284 .475 \\
\hline
\end{tabular}

Fonte: MDIC (www.mdic.gov.br)

Algumas considerações são fundamentais para se compreender o posicionamento comercial brasileiro em relação à China. Em primeiro, apesar da forte assimetria e do efeito deslocamento, tem-se a consciência que o relacionamento comercial foi e continuará sendo extremamente positivo enquanto supre cortes de importações por parte de outros países, em especial no decorrer da atual crise econômico-financeira.

Em segundo, o Brasil não se distingue somente pela posse de recursos naturais, mas igualmente por um setor manufatureiro complexo e forte e por um sistema de ciência e tecnologia com acentuado potencial. Consequentemente, a capacidade agrícola do país decorre de uma ampla sinergia entre insumos, máquinas e equipamentos, fazendo com que o agronegócio represente uma íntima conexão entre agricultura e indústria.

E, em terceiro, o Brasil, por sua vez, concentra suas importações provenientes da China em produtos eletro-eletrônicos e em máquinas e aparelhos mecânicos que, parcialmente, estão sustentando a retomada do desenvolvimento industrial brasileiro. As fortes pressões internas contra as importações chinesas estão concentradas principalmente nos setores produtores de têxteis (tecidos e vestuários) e, de brinquedos, os quais na realidade apresentam uma participação bem inferior à dos demais produtos. Como são produtos intensivos em mão-de-obra, são mais sensíveis politicamente ao afetarem, de forma mais direta, empregos no mercado doméstico. (Castro, 2008: 22-25)

De outro lado, como reflete o CEBC (2010: 3), tem-se a consciência de que as posiçôes da China permanecerão ambíguas sempre que interesses econômicos estiverem em jogo. Mas que, apesar de estar se transformando em uma potência 
internacional, continuará mantendo seu discurso de identificação como nação em desenvolvimento.

\section{Considerações finais}

No século XXI, tornou-se consensual apontar que o Brasil é um país emergente e que faz parte do principal pelotão dos países emergentes. O conceito de país emergente, ainda que não bem explicitado e passível de contestações, indica inicialmente o reconhecimento da existência de um conjunto de países que, em função de seus processos de desenvolvimento, está se aproximando dos assim denominados países desenvolvidos. Mas, mais do que isto, são igualmente países que além de apresentarem significativo crescimento econômico, demonstram intensa vontade política de co-participação nos processos decisórios internacionais, apresentando tanto ambiçôes políticas regionais quanto pretensões de se transformarem em grandes potências.

$\mathrm{Na}$ base destas pretensōes está a percepção de que, desde o final da Guerra Fria, o mundo está em um forte processo de reorganização das instituições e das regras que regulamentam as relações internacionais. Isto é, o mundo organizado, dividido e subordinado às perspectivas de dois blocos (soviético e americano) deixou de existir e se defronta agora com a presença de novos atores com capacidades e interesses de maior participação neste processo internacional de revisão e de renegociação das regras internacionais.

A crise financeira internacional, escancarada no final de 2008, bem como os impasses na Rodada Doha da OMC deixaram por demais clara a fragilidade das atuais instituiçóes existentes (com suas regras) e a necessidade de drásticas mudanças para re-acomodação dos interesses dos diferentes Estados, de forma a gerar um ambiente mais cooperativo e estável no plano internacional.

O Brasil e sua política externa expressam bem estas intenções. Em primeiro, com o final da Guerra Fria, o Brasil tomou consciência de seu isolamento internacional, em especial, pela crise financeira da década de 1980. E, em segundo, um país que se apresenta como global trader e global player, para defesa de seus interesses teria que ter uma maior presença e uma postura mais ativa nos processos negociadores internacionais.

Neste sentido, a ação política externa brasileira reintroduziu o tema da Cooperação Sul-Sul a partir da percepção de que os interesses, demandas e desejos do Sul não formam a maior parte dos termos da atual ordem internacional, conduzida pelos estados do Norte.

Esta estratégia aparenta ter o objetivo de representar parcela das aspiraçōes dos países do Sul no debate global, de forma a pressionar para o processo de reforma das instituições multilaterais. Pode, assim, ser interpretado como representando um contraponto aos países desenvolvidos, mas sem buscar um confronto, ao contrário, utilizando-se das estruturas institucionais existentes. Sendo que esta 
perspectiva é decorrente da percepção de que são Estados que detêm interesses similares, como desenvolvimento econômico, segurança e prestígio internacional.

Esta movimentação reforçou a intenção diplomática brasileira de ênfase na expansão de relações com os outros principais países em desenvolvimento, em especial com a China. De qualquer forma, é bom realçar que esta ênfase não é excludente, sendo que o Brasil persiste com a diretriz universalista de sua política externa, a qual não privilegia o mundo em desenvolvimento em detrimento do desenvolvido. Assim, é também prioritária a ampliação do relacionamento externo tanto com os Estados Unidos quanto com a União Européia ou com o Japão, ou com outras potências emergentes, como bem exemplifica o Fórum de Diálogo Índia, Brasil, África do Sul (IBAS), sem esquecer igualmente a significativa importância da América do Sul na atual política externa brasileira.

Por fim, a lembrança da aliança não escrita nos remete a Rio Branco e a sua expectativa de que o relacionamento Brasil - Estados Unidos fosse uma parceria e não uma relação de subordinação. Isto, na realidade, é o que se raciocina quando se está pensando na parceria estratégica Brasil - China, conformada por dois parceiros que embasam sua políticas externas nas perspectivas de autonomia e de não interferência e que buscam atuar internacionalmente em conjunto em questôes de interesses e de vantagens mútuas.

\section{Bibliografia}

BARBOSA, Alexandre F. \& TEPASSÊ, Ângela C. (2009). "As Relações Comerciais entre Brasil e China de 1979 a 2008: Lições de estratégia política e econômica”. IN: OLIVEIRA, Henrique Altemani. China e Índia na América Latina: desafios e perspectivas. Curitiba: Juruá Editora. PP.:193-219.

BECARD, Danielly S. R. (2009). "Cooperação e Comércio entre Brasil e China durante o Governo Lula”. IN: OLIVEIRA, Henrique Altemani. China e India na América Latina: desafios e perspectivas. Curitiba: Juruá Editora. PP.: 163-192.

CASTRO, Antonio Barros (2008). From semi-stagnation to growth in a sino-centric market”. Brazilian Journal of Political Economy, 28 (1): 3-27, January-March.

CEBC. (2010). Carta da China, Ano 7, no. 53, 27 de janeiro. 15 Pgs.

CESARIN, Sérgio M. (2009). "China e Índia en América Latina y el Caribe: enfoques comparados de inserción regional”. IN: OLIVEIRA, Henrique Altemani. China e Índia na América Latina: desafios e perspectivas. Curitiba: Juruá Editora. PP.: 20-41

CUNHA, Lílian Fernandes (2004). Em busca de um modelo de cooperação Sul-Sul - o caso da área espacial nas relaçôes entre o Brasil e a República Popular da China (1980-2003). Brasília: Universidade de Brasília, Dissertação de Mestrado.

HIRST, Monica (2008). "Brazil India Relations: a reciprocal learning process". South Asian Survey, 15 (1): 143-164.

SHANG, Deliang (2003). “Cooperação política entre China e Brasil versus multipolarização”. IN: GUIMARÃES, Samuel Pinheiro. Brasil e China: Multipolaridade. Brasília: IPRI-FUNAG. Pp.: 291-308. 
SHIXUE, Jiang (2003). "China, Latin America, and the Developing World”. IN: SMITH, Peter H.; HORISAKA, Kotaro \& NISHIJIMA, Shoji. East Asia and Latin America: The unlikely alliance. Lanham: Rowman \& Littlefield Publishers. Pp.: 311-331.

Recebido em 15 de maio de 2010 Aprovado em 18 de novembro de 2010

\title{
Resumo
}

Com base no extraordinário crescimento econômico da China, em especial após sua acessão à Organização Mundial do Comércio, o presente texto sobre o relacionamento sino-brasileiro procura determinar, de um lado, se as relações atuais podem ainda serem compreendidas dentro das perspectivas da Cooperação Sul-Sul ou se, de outro, o novo status chinês está definindo um relacionamento muito mais competitivo do que cooperativo. Procura-se igualmente avaliar se a parceria sino-brasileira pode ser definida de estratégica.

\begin{abstract}
Considering the extraordinary economic growth experienced by China in recent years, especially after its entry into the World Trade Organization, this essay on the Sino-Brazilian relationship will, while analyzing the historical process in its different dimensions, attempt to determine, on one hand, whether current relations may still be understood from the perspective of SouthSouth cooperation, and, on the other, whether the Chinese economic boom may be defining a new, much more competitive than cooperative relationship.
\end{abstract}

Palavras-chave: Relações Brasil - China, Parceria Estratégica, Cooperação Sul-Sul

Key words: Brazil-China, South-South Cooperation, Strategic Partnership 